Panorama Económico, Volumen V, No. 9, julio-diciembre, 2009, pp. 55-95

\title{
PREDICTIVE ACCURACY OF FUTURES OPTIONS IMPLIED VOLATILITY: THE CASE OF THE EXCHANGE RATE FUTURES MEXICAN PESO-US DOLLAR
}

\author{
Guillermo Benavides*
}

\begin{abstract}
RESUMEN
Existe una cantidad substancial de investigación destinada a pronosticar la volatilidad de los rendimientos de precios de futuros de activos financieros. Una parte significativa de la literatura muestra que pronosticar la mencionada volatilidad con certeza no es una tarea fácil, independientemente del modelo de pronóstico utilizado. En el presente trabajo de investigación se analiza el poder predictivo de varios modelos de pronósticos de volatilidad diaria para los rendimientos de los futuros del tipo de cambio Peso Mexicano-Dólar Estadounidense. Los modelos que se utilizan son: univariado GARCH; multi-variado GARCH (modelo BEKK); dos modelos de volatilidad implícita de opciones; y, un modelo de pronóstico compuesto. Diferente a otros trabajos en la literatura,
\end{abstract}

\footnotetext{
* Banco de México. Correo electrónico: 〈gbenavid@ @anxico.org.mx>.

I want to thank Act. Carlos Dominguez from Banco de Mexico for his grateful help in providing me with the futures options data. I also want to thank participants at the Banco de México's Economic Studies Seminar, the International Risk Management Conference at the Tecnológico de Monterrey, Campus Ciudad de México and participants at the International Finance Conference 2005 held at the University of Copenhagen in Denmark for useful comments and discussion. Finally, I greatly appreciate the very helpful suggestions from anonymous referee. Any remaining errors are my responsibility.
} 
en el presente documento se realiza un análisis más riguroso de los cálculos de la volatilidad implícita de opciones. Los resultados muestran que los modelos de volatilidad implícita de opciones fueron superiores a los modelos históricos en términos de certeza al pronosticar; y, que el modelo compuesto fue el más certero en términos del error cuadrático medio, al compararlo con el resto de los modelos. Sin embargo, los resultados deben interpretarse con prudencia dado que el coeficiente de determinación en las regresiones fue relativamente bajo. De acuerdo a los resultados se recomienda utilizar modelos de pronóstico compuesto si ambos tipos de datos, series de tiempo (históricas) y de volatilidad implícita de opciones, están disponibles.

Palabras clave: Modelos de pronóstico compuesto, tarifas de cambio, GARCH multivariado, volatilidad de opciones implicadas, pronóstico de volatilidad

Clasificación JEL: C22, C52, C53, G10

\begin{abstract}
There has been substantial research effort aimed to forecast futures price return volatilities of financial assets. A significant part of the literature shows that volatility forecast accuracy is not easy to estimate regardless of the forecasting model applied. This paper examines the volatility accuracy of several volatility forecast models for the case of the Mexican peso-USD exchange rate futures returns. The models applied here are a univariate $\mathrm{GARCH}$, a multivariate ARCH (the BEKK model), two option implied volatility models and a composite forecast model. The composite model includes time-series (historical) and option implied volatility forecasts. Different to other works in the literature, in this paper there is a more rigorous analysis of the option implied volatilities calculations. The results show that the option implied models are superior to the historical models in terms of accuracy and that the composite forecast model was the most accurate one (compared to the alternative models) having the lowest mean-squared-errors. However, the results should be taken with caution given that the coefficient of determination in the regressions was
\end{abstract}


Predictive Accuracy of Futures Options Implied Volatility:

The Case of the Exchange Rate Futures Mexican Peso-US Dollar

relatively low. According to these findings it is recommended to use a composite forecast model if both types of data are available i.e. the time-series (historical) and the option implied.

Keywords: Composite forecast models, exchange rates, multivariate GARCH, option implied volatility, volatility forecasting

JEL classifications: C22, C52, C53, G10

\section{INTRODUCTION}

There are basically two methods widely used to calculate the volatility of a financial asset. One of them is by modelling historical price returns of a specific asset and the other one is by calculating (when data is available) it option implied volatilities. Both of these procedures are explained below in it relevant literature review section (i.e. historical and option implied volatility literature review sections). Even though both methods are widely used there is a current debate about which method is the superior one predictor in terms of predicting financial asset price volatility.

Considering the existing debate in the academic literature related to the volatility forecasting accuracy between the aforementioned volatility forecasting methods in this research paper different volatility models (historical vs. option implieds) are compare to each other. The goal is to analyse which is the superior forecast model if any. It must be bear in mind that as today there are no conclusive answers about which is the most accurate method (model to) use. However, everyday there are more research papers that find that option implied volatility forecast are superior than historical ones (Poon and Granger, 2003). In the present research paper the accuracies of several volatility forecast models are compared against each other. The models presented are: 1) a Generalised Autoregressive Conditional Heteroscedasticity (GARCH) model (Bollerslev, 1986), 2) a multivariate ARCH model (Engle and Koner, 1995), 3) implied volatility estimates for European options (Black-Scholes) and American options (Barone-Adesi and Whaley, 1987) and 4) a composite forecast model (Which 
includes historical and implied volatility forecast). Different to previous works related to this topic this paper not only compares historical versus option implied volatility but also tests which option implied volatility model is superior. European option pricing models are compared to American option approximation models. Furthermore, a composite model which includes the best estimates from the historical and option implied is also compared to these models. An additional feature is that these models are applied for futures prices of an exchange rate which has not been considered for this purpose. This is done specifically for daily futures price return volatilities of the exchange rate Mexican peso-US dollar.

The layout of this paper is as follows. The historical, implied volatilities and composite approaches literature reviews are presented in section 2 . The motivation and contribution of this work is presented in sections 3 and 4 . Section 5 presents the definition of futures prices. The models are explained in section 6 . Data is detailed in section 7. Section 8 presents the descriptive statistics. The results are presented in section 9. Finally section 10 concludes (figures and tables can be observed in the Appendix).

\section{ACADEMIC LITERATURE OF VOLATILITY FORECAST MODELS}

\subsection{HISTORICAL VOLATILITY MODELS}

Historical volatility is described by Brooks (2002) as simply involving calculation of the variance or standard deviation of returns in the usual statistical way over some historical period (time frame). This variance or standard deviation may become a forecast for all future periods. Historical volatility was traditionally used as the volatility input to options pricing models although there is growing evidence that the use of volatility predicted from relatively more sophisticated time series models (ARCH models) may give more accurate option valuations (Akgiray, 1989, Chu and Freund, 1996). It is well documented that 
Predictive Accuracy of Futures Options Implied Volatility:
The Case of the Exchange Rate Futures Mexican Peso-US Dollar

ARCH models can provide accurate estimates of commodity price volatility. Just to mention a few see for example, Engle (1982), Taylor (1985) Bollerslev et al. (1992), Ng and Pirrong (1994), Susmel and Thompson (1997), Wei and Leuthold (1998), Engle (2000), Manfredo et al. (2001). However, there is less evidence that ARCH models give reliable forecasts of commodity price volatility for out-of-sample evaluation (Park and Tomek, 1989, Schroeder et al., 1993, Manfredo et al., 2001). All of them found that the explanatory power of these out-of-sample forecasts is relatively low. In most cases the $R^{2}$ are below $10 \%$ (Pong et al., 2003). ${ }^{1}$ Therefore, the forecasting ability of these models could be questionable.

\subsection{OPTION IMPLIED VOLATILITY MODELS}

Nowadays it is widely known in the forecasting-volatility-literature that the implied volatilities obtained from options prices are accurate estimators of price volatility of their underlying assets traded in financial markets (Clements and Hendry, 1998, Fleming, 1998, Blair, Poon and Taylor, 2001, Manfredo et al., 2001, Martens and Zein, 2002, Neely, 2002, Ederington and Guan, 2002, Giot, 2003). The forward-looking nature of the implied volatilities is intuitively appealing and theoretically different to the well-known conditional volatility ARCH models estimated using backward-looking historical characteristics of time series approaches. Within the academic literature there is evidence that the information content of the estimated implied volatilities from options could be superior to those estimated by time series approaches. The aforementioned evidence is supported by Fleming et al. (1995) for futures market indexes, Jorion (1995), Xu and Taylor (1995), Neely (2002) for foreign exchange, Christensen and Prabhala (1998), Figlewski (1997), Fleming (1998), Clements and Hendry (1998), Blair, Poon and Taylor (2001), Martens and Zein (2002)

1 They found that implied volatility forecasts performed at least as well as forecasts from Autoregressive Fractional Integrated Moving Average Models (ARFIMA) for time horizons of one and three months. 
for stocks, Ederington and Guan (2002) for futures options of the S\&P 500. Manfredo et al. (2001), Benavides (2003), Giot (2003), for agricultural commodities.

However, not all the research papers about option implied volatilities are positive to in terms of using this method. There are several research papers that show skepticism about the forecasting accuracy of the aforementioned implied volatilities (Day and Lewis, 1992, 1993; Figlewski, 1997, Lamoureux and Lastrapes, 1993). The latter type of research papers have increased the already existing controversy regarding which is the best method or model to use in order to obtain the most accurate volatility forecast in financial markets i.e. implied volatility against time series approaches. This is because, as yet, there are no conclusive answers about which is the best (and consistent) volatility forecast model for forecasting price returns volatilities (Manfredo et al., 2001; Brooks, 2002). For out-of-sample volatility evaluation, forecasting price return volatilities has been a very difficult task, even for option implied volatilities, given that most of the reported results in the academic literature generally have very low explanatory power i.e. low $R^{2}$.

\subsection{COMPOSITE FORECAST MODELS}

Other type of models used to forecast asset price volatility are the composite forecast models. These models are a combination of different forecast models. The aim is that by combining such models it could be possible to obtain a more accurate forecast estimate compared to the case of not being combined. The motivation to use a composite approach has to do with forecast errors. It is commonly observed that individual forecast models generally have less than perfectly correlated forecast errors. It is a belief that each of the models in the composite approach will add significant information to the model as a whole given this statistical difference in the errors. Decreasing measurement errors by averaging them with several forecast models could improve forecasting (Makridakis, 1989). It is also said that the variance of post-sample errors can be reduced considerably with composite forecast models (Clemen, 1989). 
Predictive Accuracy of Futures Options Implied Volatility:

The Case of the Exchange Rate Futures Mexican Peso-US Dollar

Composite approaches of financial asset prices started to be formally presented since the late 1960's. Some of the works are the ones of Bates and Granger (1969), Granger and Ramanathan (1984), Clemen (1989), Makridakis (1989), Kroner et al. (1994), Blair et al. (2001) for stock indexes, Fang (2002), Pong et al. (2003) for exchange rates.

In terms of non-financial empirical works there are several research papers in the literature about this topic. Some of them are the works of Bessler and Brandy (1981) which combined ARIMA and simple historical average models, and they found that for quarterly hog prices, the results were superior when these models were combined. ${ }^{2}$ They created the weights for the composite forecast model based upon the forecast ability of each individual model in terms of their Mean-Squared-Errors (MSE). Along the same lines Park and Tomek (1989) evaluated several forecast models (including ARIMA, VectorAutoregression and OLS for their variances) and concluded in favour of the composite approach. Combining several forecast models gave the lowest MSE when compared to the same models not being combined. In an opposite finding Schroeder et al. (1993) reported that forecasting cattle feeding profitability gave conflicting results. Their results show that there was no forecast model consistent enough to consider a reliable forecast model (including the composite model). Manfredo et al. (2001) attempted to forecast agricultural commodity price volatility using several models which included ARIMA, ARCH and implied volatility from options on futures contracts. They found that there was no superior model to forecast volatility (based on their MSE) however they recognised that composite approaches, which included an option implied volatility model performed marginally better than forecast models not being combined. They found that their models' $R^{2}$ were significantly low (below 10\%) and they did not find conclusive answers. They also acknowledged that composite approaches are now increasingly being used more than before. This is especially when more data (time series and option implied volatilities) are available.

${ }^{2}$ Bessler and Brandy analysed quarterly hog prices for the sample period from 1976:01 until 1979:02. 
In this research paper the idea of combining conditional and implied volatility forecasts aims specifically to test the accuracy in terms of volatility information of the composite forecast model against individual forecast models i.e. the historical and the implied volatilities models.

\section{MOTIVATION}

The motivation for conducting this research with the methods explained above i.e. the historical, the option implied volatilities and the composite approach is to extend the existing literature on exchange rate returns forecast accuracy. This is conducted by comparing these methods and evaluating them. The evaluation is performed for both in-sample and out-of-the-sample time periods. Previous research on these exchange rate volatility forecasts has ignored the early exercise privilege of the American options. This is because they use European option pricing models to find option implied volatilities of American options (see for example Pong et al., 2003). In this project both European and American option pricing models are used. The idea is to compare the forecast accuracy of both when American options are used. It was said in the literature that ignoring the early exercise privilege of the American options could cause implied volatilities series potentially flawed (Blair, Poon and Taylor, 2001). In this research paper the Barone-Adesi and Whaley (1987) approximation formula to find the price of an American option is use. Subsequently, the implied volatilities are calculated. Thus, the early exercise privilege of these American options is taken into consideration in the present study.

In addition, combination of historical (using univariate and multivariate ARCH) with option implied models aiming to forecast volatility of the Mexican peso-US dollar exchange rate futures prices has not been done before. Thus, these findings contribute with new knowledge to the existing academic literature on historical, option implied and composite forecast models applied to exchange rate futures markets. It could also be for the interest of groups of persons involved in making risk management decisions related to this exchange rate. 
Predictive Accuracy of Futures Options Implied Volatility:

The Case of the Exchange Rate Futures Mexican Peso-US Dollar

These groups of persons could be bankers, policy makers, investors, exchange rate futures traders, central banks, academic researchers among others.

\section{CONTRIBUTION}

This paper extends the work made in previous research papers related to forecast foreign exchange volatility. Firstly, several historical models are used which are commonly not used in the academic literature. These are the bivariate and tri-variate $\mathrm{ARCH}$ models. In the academic literature it is more common to observe univariate GARCH modeling trying to solve research questions about this topic. Secondly, the implied volatilities are calculated using two option price models. One of the models is for European options and the other one for American options. Most of the papers in the literature use only the European method to find the option implieds (Blair et al., 2001; Manfredo et al., 2001; Pong et al., 2003; Giot, 2003). It is then a possibility that these implied volatilities are mis-measured because they use an option valuation model for European options that does not considers the early exercise privilege of the American options for pricing the latter (Harvey and Whaley, 1992; Blair et al., 2001). Therefore the consideration of both pricing methods in this research paper allows for a more rigorous analysis of each of the methods for the option implied volatilities calculations. Thirdly, in contrast to other papers related to this topic, this research paper calculates the volatility forecast for futures prices of an exchange rate. Most of the paper in the literature show forecast for exchange rate spot prices.

Furthermore, the inclusion of the multivariate ARCH conditional volatility estimates in the composite forecast model could be a novelty to the exchange rate volatility forecasting literature. Nowadays there is strong evidence that multivariate ARCH models are more accurate than univariate ARCH models in terms of volatility forecasting of asset returns (Engle, 2000; Haigh and Holt, 2000; Pojarliev and Polasek, 2000). Thus, combining the aforementioned

estimates with the estimated implied volatilities could provide useful information 
and a rigorous examination on the performance of these volatility models. Lastly, the empirical analysis of the Mexican peso-USD exchange rate in this area is something new. Most of the works up-to-day are made on non-emerging economies' currencies. Individual characteristics of this exchange rate like for example the peso problem ${ }^{3}$ can be analysed by seeing if the models used here capture some of that exchange rate unusual behaviour.

\section{DEFINITION OF FUTURES PRICES}

As explained in previous sections, the objective of this paper is to forecast the futures price volatility of the exchange rate Mexican peso-USD. For this reason a formal definition of a futures price is explained. According to Hull (2003 p. 706) a futures price is the 'delivery price currently applicable to a future contract.' A futures contract 'obligates the holder to buy or sell an asset at a predetermined delivery price during a specified future time period. The contract is marked to market daily.' Formally the futures price can be expressed as (Hull, 2003, p. 46):

$$
F_{0}=S_{0} e^{r T}
$$

Where $F_{0}$ is the current futures (or forward) price, $S_{0}$ is the current spot price, $e$ equals the $e(\cdot)$ function, $r$ is the risk-less rate of interest per annum expressed with continuous compounding and $T$ is the time to maturity in years. For the previous formula is assumed that the underlying asset pays no income. For the case of exchange rate futures the formula is modified to adjust for the foreign interest rate. As seen in Hull (2003, p. 56) the formula can be expressed as follows,

\footnotetext{
3 In international financial markets 'the peso problem' is applied to situations where large discrete jumps in exchange rate prices or shifts on policy regimes are observed (Levich, 1998, p. 237).
} 
Predictive Accuracy of Futures Options Implied Volatility:

The Case of the Exchange Rate Futures Mexican Peso-US Dollar

$$
F_{0}=S_{0} e^{\left(r-r_{f}\right) T}
$$

where $r_{f}$ is the risk-less foreign interest rate per annum expressed with continuous compounding, which is in the same terms of the domestic interest rate described above.

Detailing of the previous equations 1 and 2 is important in this project. These are the fundamental equations that are considered in order to estimate the futures price volatilities of the exchange rate under study. Therefore the variables of futures prices, spot prices, and domestic and foreign interest rates are inputs in both the historical and option implied models. These models are explained in detail next.

\section{THE MODELS}

\subsection{HISTORICAL VOLATILITY MODELS}

The historical models under analysis are the univariate $\operatorname{GARCH}(p, q)$ and a restricted version of the multi-variate $\operatorname{ARCH} \operatorname{BEKK}(p, q)$ model proposed by Engle and Kroner (1995). The BEKK model (named like this after an earlier working paper by Baba, Engle, Kraft and Kroner (Baba et al., 1992)) is used in order to estimate the historical volatilities of the exchange rate under study in a multi-variate framework. The former estimates the conditional variances. The latter, in addition to estimating the conditional variances, also estimates the conditional covariances of the series under study. The BEKK model can be useful to test economic theories which involve price volatility analysis like for example price uncertainty influences to employment (Engle and Kroner, 1995), volatility relationships between financial assets i.e. CAPM volatility Bollerslev et al. (1988), hedge ratio volatility for FTSE stock index returns Brooks, Hendry and Persand (2002). It is also possible to test futures markets theories like the Samuelson Hypothesis (Samuelson, 1965). The latter states that spot prices 
are more volatile than futures prices. This could be tested with the previously mentioned BEKK model.

In the present paper the univariate $\operatorname{GARCH}(1,1)$ model is estimated applying the standard procedure as explained in Taylor (1985) and Bollerslev (1986). The formulae for the $\operatorname{GARCH}(1,1)$ is presented next. For the model there are two main equations. These are the mean equation and the variance equation:

Mean equation,

$$
\begin{gathered}
\Delta y_{t}=\mu+e_{t} \\
e_{t^{1} / 2} I_{t-1} \sim N\left(0, h_{t}\right),
\end{gathered}
$$

Variance equation,

$$
h_{t}=\alpha_{0}+\alpha_{1} e_{t-1}^{2}+\beta_{1} h_{t-1}
$$

Where: $y_{t}=\log$ of the series under analysis (exchange rate) at time $t, h_{t}=$ variance at time $t$ and $t-1$ for $h_{t-1}, \Delta=$ first differences of the series, $e_{t}$ error term at time $t$, $I_{t-1}$ is the information set at time $t-1, \grave{\imath}, \ddot{o}, \alpha_{0}, \alpha_{1}, \beta_{l}$ are parameters and $N\left(0, h_{t}\right)$ is for the assumption that the log returns are normally distributed. In other words, assuming a constant mean $i$ (the mean of the series $y_{t}$ ) the distribution of $e_{t}$ is assumed to Gaussian with zero mean and variance $h_{t}$. The parameters were estimated using maximum likelihood method using the BHHH (Berndtand, Hall, Hall, and Hausman) algorithm of Berndt et al. (1974). The Bollerslev and Wooldridge (1992) methodology was used to estimate the standard errors. The procedure to obtain the BEKK model mentioned above is explained in equations 5 - 9 below.

Let $y_{t}$ be a vector of returns at time $t$ (in this research paper the dimension of this vector is $2 \times 1$ given that there are two series under analysis, spot and futures prices series, but in any different case it could be extended to a $n \times 1$ vector),

$$
y_{t}=\mu+\varepsilon_{t}
$$


Predictive Accuracy of Futures Options Implied Volatility:

The Case of the Exchange Rate Futures Mexican Peso-US Dollar

Where $\mu$ is a constant mean vector and the heteroscedastic errors $\varepsilon_{t}$ are multivariate normally distributed ( $\mu=$ greek-small-letter-mu and $\varepsilon=$ greeksmall-letter-epsilon)

$$
\varepsilon_{t} I_{t-1} \sim N\left(0, H_{t}\right)
$$

Each of the elements of $H_{t}$ depends on $q$ lagged values of the squares and the cross products of $\varepsilon_{t}$ as well as they on the $p$ lagged values of $H_{t}(H=$ greekcapital-letter-eta).

Considering a multivariate model setting it is convenient to stack the nonredundant elements of the conditional covariance matrix into a vector i.e. those elements on and below the main diagonal. The operator, which performs the aforementioned stacking, is known as the vech operator. Defining $h_{t}=v e c h\left(H_{t}\right)$ and $\eta_{t}=\operatorname{vech}\left(\varepsilon_{t} \varepsilon_{t}^{\prime}\right)$ the parameterisation of the variance matrix is ( $=$ greeksmall-letter-eta).

$$
h_{t}=\alpha_{0}+\alpha_{1} \eta_{t-1}+\ldots+\alpha_{q} \eta_{t-q}+\beta_{1} h_{t-1}+\ldots+\beta_{p} h_{t-p} .
$$

Equation 6 above is called the vech representation. Bollerslev et al. (1988) have proposed a diagonal matrix representation, in which each element in the variance matrix $h_{j k, t}$ depends only on past values of itself and past values of the cross product $\varepsilon_{j, t} \varepsilon_{k, t}$. In other words, the variances depend on their own past squared residuals and the covariances depend on their own past cross products of the relevant residuals. A diagonal structure of the matrices $\alpha_{i}$ and $\beta_{i}$ is assumed in order to obtain a diagonal model in the vech representation shown in equation 2 above ( $\alpha=$ greek-small-letter-alpha and $\beta=$ greek-small-letter-beta).

In the representations explained above it is difficult to ensure positive definiteness in the estimation procedure of the conditional variance matrix. To ensure the condition of a positive definite conditional variance matrix in the optimisation process Engle and Kroner (1995) proposed the BEKK model. This model representation can be observed below in equation 7 . 


$$
H_{t}=\omega \omega^{\prime}+\sum_{i=1}^{q} \alpha\left(\varepsilon_{t-i} \varepsilon_{t-i}^{\prime}\right) \alpha^{\prime}+\sum_{i=1}^{p} \beta H_{t-i} \beta^{\prime}
$$

In equation 7 above $\omega \omega^{\prime}$ is symmetric and positive definite and the second and third terms in the right-hand-side of this equation are expressed in quadratic forms ( $=$ greek-small-letter-omega). This ensures that $H_{t}$ is positive definite and no constraints are necessary on the $\alpha_{i}$ and $\beta_{i}$ parameter matrices. As a result, the eigen values of the variance-covariance matrix will have positive real parts which satisfy the condition for a positive definite matrix.

For an empirical implementation and without loss of generality the BEKK model can be estimated in a restricted form having $\omega$ as a $2 \times 2$ lower triangular matrix, $\alpha$ and $\beta$ being $2 \times 2$ diagonal matrices. Thus, for the bivariate case the BEKK model (BVBEKK) can be expressed in the following vector form:

$$
\begin{aligned}
{\left[\begin{array}{ll}
H_{11, t} & H_{12, t} \\
H_{12, t} & H_{22, t}
\end{array}\right]=} & {\left[\begin{array}{cc}
\omega_{1} & 0 \\
\omega_{2} & \omega_{3}
\end{array}\right]\left[\begin{array}{cc}
\omega_{1} & \omega_{2} \\
0 & \omega_{3}
\end{array}\right]+\left[\begin{array}{cc}
\alpha_{1} & 0 \\
0 & \alpha_{2}
\end{array}\right]\left[\begin{array}{cc}
\varepsilon_{1, t-1}^{2} & \varepsilon_{1, t-1} \varepsilon_{2, t-1} \\
\varepsilon_{1, t-1} \varepsilon_{2, t-1} & \varepsilon_{2, t-1}^{2}
\end{array}\right]\left[\begin{array}{cc}
\alpha_{1} & 0 \\
0 & \alpha_{2}
\end{array}\right] } \\
& +\left[\begin{array}{cc}
\beta_{1} & 0 \\
0 & \beta_{2}
\end{array}\right]\left[\begin{array}{ll}
H_{11, t-1} & H_{12, t-1} \\
H_{12, t-1} & H_{22, t-1}
\end{array}\right]\left[\begin{array}{cc}
\beta_{1} & 0 \\
0 & \beta_{2}
\end{array}\right]
\end{aligned}
$$

or

$$
\begin{gathered}
H_{11 t}=\omega_{1}^{2}+\alpha_{1}^{2} \varepsilon_{1 t-1}^{2}+\beta_{1}^{2} H_{11 t-1} \\
H_{22 t}=\omega_{2}^{2}+\omega_{3}^{2}+\alpha_{2}^{2} \varepsilon_{2 t-1}^{2}+\beta_{2}^{2} H_{22 t-1} \\
H_{12 t}=H_{21 t}=\omega_{1} \omega_{2}+\alpha_{1} \alpha_{2} \varepsilon_{1 t-1} \varepsilon_{2 t-1}+\beta_{1} \beta_{2} H_{12 t-1}
\end{gathered}
$$

Following the procedure for the bi-variate case a tri-variate model (TVBEKK) could also be estimated. Thus, the specification for the tri-variate case is as follows: 
Predictive Accuracy of Futures Options Implied Volatility:

The Case of the Exchange Rate Futures Mexican Peso-US Dollar

$$
\begin{gathered}
H_{11 t}=\omega_{1}^{2}+\alpha_{1}^{2} \varepsilon_{1 t-1}^{2}+\beta_{1}^{2} H_{11 t-1} \\
H_{22 t}=\omega_{2}^{2}+\omega_{4}^{2}+\alpha_{2}^{2} \varepsilon_{2 t-1}^{2}+\beta_{2}^{2} H_{22 t-1} \\
H_{33 t}=\omega_{3}^{2}+\omega_{5}^{2}+\omega_{6}^{2}+\alpha_{3}^{2} \varepsilon_{3 t-1}^{2}+\beta_{3}^{2} H_{33 t-1} \\
H_{12 t}=H_{21 t}=\omega_{1} \omega_{2}+\alpha_{1} \alpha_{2} \varepsilon_{1 t-1} \varepsilon_{2 t-1}+\beta_{1} \beta_{2} H_{12 t-1} \\
H_{13 t}=H_{31 t}=\omega_{1} \omega_{3}+\alpha_{1} \alpha_{3} \varepsilon_{1 t-1} \varepsilon_{3 t-1}+\beta_{1} \beta_{3} H_{13 t-1} \\
H_{23 t}=H_{32 t}=\omega_{2} \omega_{3}+\omega_{4} \omega_{5}+\alpha_{2} \alpha_{3} \varepsilon_{2 t-1} \varepsilon_{3 t-1}+\beta_{2} \beta_{3} H_{23 t-1}
\end{gathered}
$$

In the bi-variate model the variables used are spot prices $\left(y_{1}\right)$ and futures prices $\left(y_{2}\right)$. These variables are use by relevance to the theoretical price equation 1 , which has both of the variables. For the tri-variate case in addition to $y_{1}$ and $y_{2}$ a new variable is added. This is the interest rate $\left(y_{3}\right)$, which could be the domestic and the foreign interest rate. ${ }^{4}$ The theoretical justification is equation 2 that defines the theoretical price for the exchange rate futures price. Again, for these models maximum likelihood methodology and the BHHH algorithm were used in the estimation procedure. The specification of these historical ( $p$, $q$ ) models is chosen applying the Akaike Information Criterion (AIC) ${ }^{5}$ It was found that the parsimonious first order specification was the optimal one for all of them.

\subsection{THE OPTION IMPLIED VOLATILITY MODELS}

The option implied volatility of an underlying asset is the market's forecast of the volatility of that asset and this is obtained with the options written on that

${ }^{4}$ The risk-free interest rates for both countries $(r f)$ were used. The results were qualitatively similar. However, the interest rates of the U.S. were chosen for the Mean-Square-Error evaluation.

5 The AIC is obtained with the following formula: $\frac{-2 l}{n}+\frac{2 k}{n}$. Where $l$ is the value of the $\log$ likelihood function using the $k$ estimated parameters, $k$ is the number of estimated parameters and $n$ is the number of observations. 
underlying asset (Hull: 2003). To calculate an option implied volatility of an asset an option valuation model is needed as well as the inputs for that model, like the risk free rate of interest, time to maturity, price of the underlying asset, the exercise price and the price of the option (Blair, Poon and Taylor: 2001). Using an inappropriate valuation model will produce pricing errors and the option implied volatilities will be mis-measured (Harvey and Whaley: 1992). For example using a valuation model that does not considers the early exercise privilege of an American option to find the option implied volatilites from American options will produce errors in the calculations i.e. using the Black and Scholes (1973) model (henceforth, the Black-Scholes model) to find the option implied volatilites from American options. ${ }^{6}$ In this research paper two option pricing models are used. One of them is the BS and the other one is an option valuation model that gives an approximation for American options. The latter is a model developed by Barone-Adesi and Whaley (1987) henceforth BAW. The BAW model is used given that this valuation model takes into consideration the early exercise privilege of American options thus; mis-measurement errors from an early exercise are avoided.

The BS is used in order to compare both models and test which has a superior predictive accuracy. The assumptions made for this model are: 1) Interest rates are non-stochastic, which means that the forward is equal the futures price. 2) There are no arbitrage profits, so at equilibrium equation 2 above holds. 3) All options are European. 4) The agents are risk-neutral, 5) there are no transaction costs and 6) the prices follow a Geometric Brownian Motion. The BS for exchange rates is stated formally in equation 10 below.

$$
c=S e^{-r f T} N\left(d_{1}\right)-X e^{-r T} N\left(d_{2}\right)
$$

\footnotetext{
6 The Black-Scholes option valuation model is for European options. These options do not have the early exercise privilege that American options have.
} 
Predictive Accuracy of Futures Options Implied Volatility:

The Case of the Exchange Rate Futures Mexican Peso-US Dollar

$$
d_{2}=d_{1}-\sigma \sqrt{T}
$$

Where small $c$ is the value of the European call option, $T$ represents the time to maturity of the option, $N(x)$ is the cumulative probability distribution function which is normally distributed. In other words, the probability that a variable with a standard normal distribution, $\psi(0,1)$ will be less than $x$. The exercise price is represented by $X, \ln$ is the natural logarithm and $\sigma$ (small-letter-sigma) is the asset's volatility measured as it standard deviation. The other variables are the same as defined previously.

The assumption made for the BS model also apply to the BAW model with the exception that the options are assumed American not European. This BAW

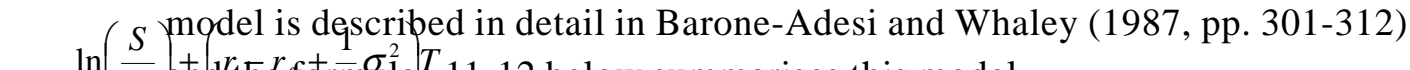

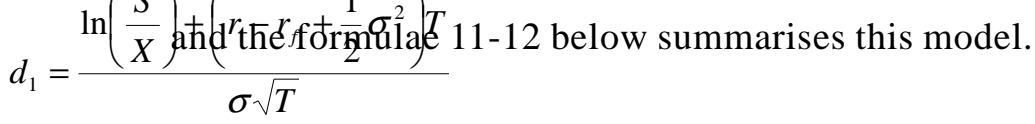

$$
C(S, T)=c(S, T)+A_{2}\left(\frac{S}{S^{*}}\right)^{q_{2}}
$$

when $S<S^{*}$, and

$$
C(S, T)=S-X
$$

when $S \geq S^{*}$, where

$$
A_{2}=\left(\frac{S^{*}}{q_{2}}\right)\left\{1-e^{(b-r) T} N\left[d_{1}\left(S^{*}\right)\right]\right\}
$$


and,

$$
d_{1}\left(S^{*}\right)=\frac{\left[\ln \left(\frac{S^{*}}{X}\right)+\left(b+0.5 \sigma^{2}\right) T\right]}{\sigma \sqrt{T}}
$$

The variables in the formulae above represent the following: capitol $C$ is equal to the American call option price, $c$ is equal to the Black-Scholes value for an European call, $S^{*}$ is the value of the exercise boundary (exercise now only if $S>S^{*}$ ). $q_{2}$ is an eigen value obtained (mathematically) from an early exercise premium differential equation as explained in Barone-Adesi and Whaley (1987, p. 306). The variable $b$ is equal to the cost of carry, $r$ is the riskless rate of interest, $N$ [.] is the cumulative univariate normal distribution, $\sigma^{2}$ is the instantaneous variance and $\sigma$ is the instantaneous standard deviation, which is a proxy for the asset's price volatility ( $\sigma=$ greeksmall-letter-sigma). $S^{*}$ is found with an algorithm which is described in detail in Barone-Adesi and Whaley (1987, p. 309). In this research paper $S$ is equal to the exchange rate futures price $F$ given that the option implied volatilities under analysis are those of the exchange rate futures prices.

The implied volatility is calculated by an iterative process solving for the only unobserved variable, which is $\sigma$ in the call option price function $c(S, X, T$, $\left.r, r_{f} \sigma\right)$. Having set up the BS and BAW formulas and knowing the value of the observed variables $c, S, X, T, r, r_{f}$ the implied volatility is found by allowing $\sigma$ to depend on itself plus a change dependent on the magnitude the calculated option price differs from the traded price (so, it will go up if the calculated price is below the traded price and vice versa). The calculation is done several times until the pricing error becomes negligible. ${ }^{7}$ For each trading day the

\footnotetext{
7 These calculations were performed using Visual Basic for Applications computer language.
} 
Predictive Accuracy of Futures Options Implied Volatility:

The Case of the Exchange Rate Futures Mexican Peso-US Dollar

aforementioned implied volatilities are derived from nearby to expiration futures options contracts (at least fifteen trading days prior to expiration) by taking the at-the-money (or the closest to at-the-money) call options price for the exchange rate Mexican peso-USD. In other words, the futures contract exercise price is matched against the call option futures price, which is at-the-money (equal) or the closest to at-the-money (almost equal). This is done for every trading day until the option contract is fifteen trading days close to expiration. When the option is fifteen trading days to expiration the implied volatilities are calculated with the next (in calendar) futures option contract. This is done in order to avoid volatility bias due to time to expiration phenomena (Figlewski, 1997). The relevant interest rate is used for each trading day in order to calculate these implied volatilities.

\subsection{THE COMPOSITE FORECAST MODEL}

In the spirit of Makridakis (1989) a composite forecast model is also estimated. The composite forecast model includes the estimates of the implied volatilities as well as the estimates from the BEKK model. Considering that the time variable in the option price formula is measured in years the estimates of the implied volatilities are calculated on an annualised basis. In order to include the implied volatilities estimates in the composite forecast model they must be transformed into daily trading-days estimates and then extended to a desired forecast horizon. Following Manfredo et al. (2001) the formula to transform the aforementioned annualised estimates into daily trading-days implied volatilities which then can be extended to a desired forecast horizon is presented in equation 13 below.

$$
\sigma_{t, h r}=I V_{t} \cdot \frac{\sqrt{h} r}{\sqrt{252}}
$$

In equation 13 above $\sigma_{t, h r}$ represent the $h r$-period volatility forecast for the exchange rate at time $t$. The symbol $I V_{t}$ represents the implied volatility estimate 
(annualised) at time $t$. The $h r$ represents the desired forecast horizon. Considering that the daily implied volatilities estimates are obtained on an annualised basis with daily data the numerator in equation 13 above is one, which represents onetrading-day (in other words the forecast is made for one trading day) and the denominator (the number 252) represent the number of trading days in one year.

In order to create the composite forecast model it is necessary to use a simple averaging technique where the composite forecast is merely the average of individual forecasts at time $t$. It follows that weights for each of the volatility forecasts are generated by an ordinary least squares (OLS) regression of past realised volatility on the respective volatility forecasts. This procedure to create the weights for the aforementioned composite volatility forecast is explained in more detail in Granger and Ramanathan (1984). This can be observed in equation 14 below.

$$
\sigma_{t}=\alpha_{0}+\beta_{1} \sigma_{1, t}+\beta_{2} \sigma_{2, t}+\ldots+\beta_{k} \sigma_{k, t}+\varepsilon_{t}
$$

In equation $14 \sigma_{t}$ above represent the realised volatility at time $t, \sigma_{k, t}$ represent the individual volatility forecast $(k)$ corresponding to the realised volatility at period $t$. As it can be observed in this equation the composite forecast model includes the average of the individual volatility forecasts at time $t$. Following Blair, Poon and Taylor (2001) the realised volatility can be calculated in the following way,

$$
\sigma_{t, h r}^{2}=\sum_{j=1}^{h r} R_{t+j}^{2}
$$

In equation 15 above $\sigma_{t, h r}$ represents the realised (total) volatility at time $t$ over the forecast horizon $h r$. The $R^{2}{ }_{t}$ represents the squared return at time period $t$. Thus, the resulting composite volatility forecast can be observed in equation 16 below.

$$
\sigma_{t+1}=\hat{\alpha}_{0}+\hat{\beta}_{1} \sigma_{1, t+1}+\hat{\beta}_{2} \sigma_{2, t+1}+\ldots+\hat{\beta}_{k} \sigma_{k, t+1}
$$


Predictive Accuracy of Futures Options Implied Volatility:
The Case of the Exchange Rate Futures Mexican Peso-US Dollar

In equation 16 above the variables are the same as expressed previously. The composite forecast model of this equation is a one-day volatility forecast. In order to create a composite volatility forecast of more than one day i.e. $h r>1$ the estimated one-day composite volatility forecast (from equation 16 above) is multiplied by $\sqrt{h} r$. The aforementioned method for obtaining a composite volatility forecast of more than one day $(h>1)$ is a common practice in the academic literature however, it is important to emphasise that an alternative is to obtain predictions of volatility for each period in the forecast interval (e. g. from an ARCH model).

The MSE obtained from each of the estimates of all the volatility forecast models are compared to each other. The formula to obtain the MSE is presented in equation 17 below.

$$
M S E=\frac{1}{n} \sum_{i=1}^{n}\left(\sigma_{t, h r, i}^{2}-\sigma_{t-1, h r, i}\right)^{2}
$$

In equation 17 above $n$ is equal to the number of observations and the other variables are the same as described previously. These MSE comparisons are performed in order to provide a robust analysis of the accuracy of the aforementioned composite volatility forecast model against the alternative models (the conditional and implied volatilities models). The model with the smaller MSE is considered the most accurate volatility forecasting model of the returns of the exchange rate. Ranking models in terms of their MSE is a common practice in the forecasting volatility literature (Manfredo et al., 2001).

\section{DATA}

\subsection{FUTURES AND SPOT DATA}

The data for the exchange rate Mexican peso-USD consists of daily spot and futures prices obtained from the Central Bank of Mexico web page 
database $^{8}$ and futures contracts traded at the Chicago Mercantile Exchange (CME) respectively. The sample period under analysis is two years and four months from 03/09/2001 to 05/01/2004 supplied by Infosel's database. The sample size is 597 observations. The sample period was chosen considering that it covers sufficient numbers years after important economic events in the Mexican economy. For example the starting of the floating-currency regime in 1994, the Central Bank autonomy and the implementation of the North America Free Trade Agreement (NAFTA) in the same year.

\subsection{OPTIONS DATA}

The options data consists of daily options prices for futures contracts the Mexican peso-USD traded at the CME. The sample period under analysis is two years from 02/01/2002 to 05/01/2004 supplied by Reuter's database. The sample size is 513 observations. The data for the interest rates consists of daily 30-day and 91-day interest rates of US Certificates of Deposit (CD's) obtained from the FED web page ${ }^{9}$ and same maturity Mexican CD's obtained form the Central Bank of Mexico web page. The options data is necessary in order to estimate the implied volatilities for the futures price exchange rate.

\subsection{DATA TRANSFORMATION}

In order to avoid unrealistic "jumps" when creating a time-series of futures prices from different contracts (Wei and Leuthold, 1998), synthetic futures prices were created. These were calculated by a "roll-over" procedure that is basically an interpolation of futures prices from different maturity futures contracts. This procedure creates a constant maturity weighted average futures price based

\footnotetext{
${ }^{8}$ The Central Bank of Mexico web page is < http://www.banxico.org.mx>.

9 The web page is < http://www.federalreserve.gov/>.
} 
Predictive Accuracy of Futures Options Implied Volatility:

The Case of the Exchange Rate Futures Mexican Peso-US Dollar

upon the futures prices and the days to maturity of the two near-by-expiration

contracts. ${ }^{10}$ The formula used to obtain the synthetic futures price ${ }^{11}$ is shown below in equation 18 .

$$
S Y N_{T}=F_{j}\left[\frac{\left(T-T_{i}\right)}{\left(T_{j}-T_{i}\right)}\right]+F_{i}\left[\frac{\left(T_{j}-T\right)}{\left(T_{j}-T_{i}\right)}\right]
$$

Where: $S Y N_{T}=$ Synthetic futures price for delivery at $T, F_{j}=$ Contract $j$ futures price expiring at $j, F_{i}=$ Contract $i$ futures price expiring at $i, T=91$, the chosen constant maturity in number of days, $T_{i}=$ Contract $i$ expiration in days remaining, $T_{j}=$ Contract $j$ expiration in days remaining, $j=i+1$, with $T_{i} \leq T \leq T_{j}$.

The time to expiration of the synthetic futures prices calculated is $T=91$ days. This is considered an appropriate time-to-expiration given that a shorter time-to-expiration will give higher expected volatility. This situation is observed in empirical research papers, which have found that volatility in futures prices increases, as a contract gets closer to expiration (Samuelson, 1965). A higher expected volatility due to time-to-expiration could have biased the results of this analysis. Thus, 91-day synthetic futures prices were considered appropriate using this method in order to avoid high volatility estimates due to time-to-expiration causes. In addition this will always allow finding a shorter and longer contract, if necessary to do more analysis regarding time to maturity of the contracts.

\section{DESCRIPTIVE STATISTICS}

This subsection presents the descriptive statistics for the realised volatilities of the exchange rate futures returns and the volatility forecasting models. The

${ }^{10}$ The futures contracts for the aforementioned exchange rate at the CME have the following delivery months: March, June, September and December.

${ }^{11}$ The concepts synthetic futures price and futures price are synonymous for the rest of the paper. 
sample sizes for the $\operatorname{GARCH}(1,1)$, the bi-variate and tri-variate $\operatorname{BEKK}(1,1)$ models are from 03/09/2001 to 05/01/2004. The sample sizes of the realised volatilities, the option implieds and the composite forecast models are from $02 / 01 / 2002$ to $05 / 01 / 2004$. The sample sizes for the historical models (conditional autoregressive models) are larger given that more data was available for the author. Prior to fitting the ARCH models ARCH effects tests were conducted on the series under analysis. This was done in order to see if the series had ARCH effects therefore to make sure that these types of models are appropriate for the data. The test conducted was the ARCHLM test following the procedure of Engle (1982). According to the results it was shown that all the series under study i.e. the spot, futures prices and the interest rates had ARCH effects. ${ }^{12}$ Under the null of homoscedasticity in the errors the $F$-statistics were 3.7620 for the spot, 7.6433 for the futures and 19.7698 for the US interest rates. Therefore the null hypothesis was rejected in favour of heteroscedasticity on those errors.

Figure 1 presents the natural logarithms (logs) of the spot and futures prices in terms of Mexican pesos per USD and the realised volatility of the synthetic futures price. The realised volatility graph is truncated at 0.002 . Two observations are not observed in the graph which are for the days 13/03/2003$14 / 03 / 2003$ were it was observed higher than usual volatility.

Table 1 show the descriptive statistics for the realised volatility and the forecasting models. As it can be observed in Table 1 the means of the option implied and the variances of the realised volatilities are the ones with higher values. These findings are consistent with Christensen and Prabhala (1998) who found that the means of the option implieds were higher than the means of the realised volatilities and that the variances of the realised volatilities were higher than the variances of the option implieds. The distributions in that table

\footnotetext{
12 These tests were conducted regressing the logarithmic returns of the series under analysis against a constant. The ARCH-LM test is the performed on the residuals of that regression. The test consists on regressing the square residuals against a constant and lagged values of the same square residuals. Five lags were applied on each test.
} 
Predictive Accuracy of Futures Options Implied Volatility:
The Case of the Exchange Rate Futures Mexican Peso-US Dollar

are highly skewed and leptokurtic indicating non-normality of the returns and the forecast estimates. This is consistent with the work of Wei and Leuthold (1998) who analysed volatility in futures markets and had similar findings with daily futures price volatility.

Lastly, figures 2 and 3 presents the observations of the realised volatility (top line) and the estimates of the historical models, the option implieds and the composite forecast model. Again, the realised volatility graph is truncated at 0.002 . It can be observed that in both graphs all of the models capture the high volatility periods shown with the realised volatility. At simple sight the implied volatility models estimates are almost the same.

\section{RESULTS}

\subsection{IN-SAMPLE EVALUATION}

The OLS estimates for the weights of the composite forecast model (equation 14 above) and the results of the MSE are presented in tables 2-3. In Table 2 the third row presents the estimates of the regression of the realised volatility against the historical TVBEKK $(1,1)$ model. The fourth row presents the estimates of the regression of the realised volatility against the BS implied volatility model. The last column presents the estimates of the regression of the realised volatility against both of the models. The weights are taken from the last row. The TVBEKK and BS models were chosen given that they had superior forecast accuracy in terms of MSE. As it can be observed in Table 2 the OLS estimates show that the implied volatilities contain more of the information content of the realised volatility for the returns when they are compared with the other forecast models. However, it is difficult to find conclusive answers about their statistical power because the adjusted $R^{2}$ are remarkably low i.e. 0.0599 .

In Table 3 it can be observed that the most accurate model is the composite forecast model given that it has the lowest MSE. These results are consistent 
with Kroner et al. (1994), Blair, Poon and Taylor (2001) and Manfredo ${ }^{13}$ et al. (2001), Fang (2002) who found the most accurate volatility forecasts using composite forecast models. The second best returns volatilities forecasts are the implied volatility models not being combined. These results are consistent to that part of the literature who argues in favour of option implied volatility in terms of forecasting accuracy. The differences of the MSE among the models in Table 3 are statistically significant at the $1 \%$ level. The $p$-values rejected the null hypothesis of equality of forecast accuracy at that level. The null hypothesis is the composite forecast against each of the remaining models. By rejecting the null it means that there is statistical significant difference between the forecasts of the two models evaluated. The procedure applied to obtain these statistical significances is the same as the one described in Diebold and Mariano (1995). ${ }^{14}$

\subsection{OUT-OF-THE-SAMPLE EVALUATION}

The sample period under analysis is partitioned in order to evaluate the outof-the-sample forecasts. The estimates (in-sample) for all the models are obtained from $2^{\text {nd }}$ January 2002 to $30^{\text {th }}$ December 2002 for a total of 256 observations (about half the total number of observations). The jump-off period is $31^{\text {st }}$

${ }^{13}$ In Manfredo et al. (2001) the forecast time horizon was a one-week volatility forecast for the case of corn.

${ }^{14}$ This method requires generating a time series, which is the differential of the squaredforecast errors from two different forecast models i.e. $d_{t}=\left(\sigma_{t}^{2}-\hat{\sigma}_{1, t-1}\right)^{2}-\left(\sigma_{t}^{2}-\hat{\sigma}_{2, t-1}\right)^{2}$, where $d_{t}$ is the differential of the series and $\hat{\sigma}_{i}$ is the forecast of the $i$ model. The $t$-statistic is obtained in the following way, $\frac{\bar{d}}{\sqrt{\frac{s d}{n}}}$ where $\bar{d}$ is the sample mean and $s d$ is equal to the standard deviation of the series. The other variables are the same as described previously. 
Predictive Accuracy of Futures Options Implied Volatility:

The Case of the Exchange Rate Futures Mexican Peso-US Dollar

December 2002, thus the out-of-the-sample evaluation for all the forecasting models is from $31^{\text {st }}$ December 2002 to $5^{\text {th }}$ January 2004. The estimates (weights) of the OLS regressions (equation 14 above) and the out-of-the-sample results of the MSE can be observed in table 4-5 respectively.

The variables chosen for the composite model were the ones with superior forecast accuracy (lowest MSE) in the in-sample evaluation. These were the tri-variate ARCH for the historical and the Black-Scholes for the option implied. The results of the estimates for each variable alone in addition to the composite weights are presented in Table 4. According to these estimated parameters in Table 4, it is possible to observe that the option implied contains more information of the realised volatility compared to the historical volatility model (TVBEKK). The out-of-the-sample evaluation shows that the results are qualitatively similar to the in-sample evaluation (Table 3) although not the same. The composite forecast models were the most accurate models in the in-sample evaluation. However it was shown that within the composite specification the option implied is the best model in terms of the relevant information about the realised volatility i.e. out performing the TVBEKK $(1,1)$ model. ${ }^{15}$ That was consistent in both evaluation procedures: the in-sample and the out-of-the-sample. It can be observed in Table 5 that for the out-of-the-sample evaluation the option implied models have the lowest MSE thus, they were the most accurate models for forecasting futures returns of the exchange rate under analysis. The second in superiority was the composite model performing with more accuracy if compared with the historical models. The MSE differences in this table are statistically significant at the $5 \%$ level. The null hypothesis is the option implied models against each of the remaining models.

15 Additional specifications in the composite model were also tried. The results were qualitatively similar showing more information content from options than from historical models (GARCH, BVBEEK). 


\section{CONCLUSION}

The on-going debate related to which is the most accurate model to forecast volatility of price returns of financial assets has led academic researchers to foster empirical research on the aforementioned topic. A considerable amount of research projects have compared time-series models against option implied volatilities and for instance composite forecast models. The objective is to find the most accurate model (historical, option implied or combined) to forecast price return volatility for specific assets. Albeit part of the literature advocates the use of option implied volatilities as the most accurate alternative to forecast price returns volatilities there are still no conclusive answers in terms of finding one superior model. This is because the coefficients of determination are usually relatively low for all models.

In this paper the aforementioned volatility forecast models i.e. time-series, option implied and composite forecast models were compared to each other in order to find the most accurate volatility forecasting model for the futures price returns of the Mexican peso-US Dollar exchange rate. According to the results the implied volatilities contained most of the information content of the realised return volatility for that exchange rate time series. Similar findings can be found in the academic literature for agricultural commodities, stock prices and stock indexes. The results also show that the composite forecast model was the most accurate model in an in-sample evaluation when they were compared to the alternative models not being combined. For the outof-the-sample evaluation the implied volatility forecasts proved to be superior to the other models. In terms of in-sample evaluation, these findings are consistent with part of the academic literature, which states that composite approaches are the most accurate alternative to forecast price returns volatilities. However, these results should be taking with caution given the low statistical power of the regressions (low coefficients of determination). Nonetheless, it is recommended that in order to have the most accurate volatility forecast both type of data i.e. historical and option implied should be used within a composite forecast framework. Especially if both type of data are available. 
Predictive Accuracy of Futures Options Implied Volatility:
The Case of the Exchange Rate Futures Mexican Peso-US Dollar

\section{REFERENCES}

Akgiray, V. (1989), "Conditional Heteroscedasticity in Time Series of Stock Returns: Evidence and Forecasts", Journal of Business, Vol. 62 (55-80).

Baba, Y., R. F. Engle, K. F. Kroner and D. Kraft (1992), "Multivariate Simultaneous Generalized ARCH”, Economics Working Paper 92-5, University of Arizona, Tucson.

Barone-Adesi, G. and R. E. Whaley (1987), "Efficient Approximation of American Option Values", The Journal of Finance, Vol. 42, June (301-320).

Bates, J. M. and C. W. J. Granger (1969), "The Combination of Forecasts", Operations Research Quarterly, Vol. 20 (451-468).

Benavides, G. (2003), "Price Volatility Forecasts for Agricultural Commodities: An Application of Historical Volatility Models, Option Implieds and Composite Approaches for Futures Prices of Corn and Wheat", Workingpaper.

Berndtand, E., B. Hall, R. Hall and J. Hausman (1974), "Estimation and Inference in Nonlinear Structural Models", Annals of Economic and Social Measurement (653-665).

Bessler, D. A. and J. A. Brandy (1981), "Forecasting Livestock Prices with Individual and Composite Methods", Applied Economics, Vol. 13 (513-522).

Black, F. and M. S. Scholes (1973), "The Pricing of Options and Corporate Liabilities", Journal of Political Economy, Vol. 81, May-June (637-654).

Blair, B. J., S. Poon and S. J. Taylor (2001), "Forecasting S\&P 100 Volatility: The Incremental Information Content of Implied Volatilities and High-Frequency Index Returns", Journal of Econometrics, Vol. 105 (5-26).

Bollerslev, T. P. (1986), "Generalized Autoregressive Conditional Heteroscedasticity”, Journal of Econometrics, Vol. 31 (307-327).

Bollerslev, T., R. Engle and J. Wooldridge (1988), “A Capital Asset Pricing Model with Time-Varying Covariances", Journal of Political Economy, No. 96 (116-131).

Bollerslev, T. P., R. Y. Chou and K. F. Kroner (1992), "ARCH Modelling in Finance: A Review of the Theory and Empirical Evidence", Journal of Econometrics, 52 (5-59). 
Brooks, C., O. T. Henry and G. Persand (2002), "Optimal Hedging and the Value of the News", Journal of Business, Vol. 75, Issue 2 (333-52).

Brooks, C. (2002), Introductory Econometrics for Finance, Cambridge University Press.

Christensen, B. J. and N. R. Prabhala (1998), "The Relation between Implied and Realized Volatility”, Journal of Financial Economics, Volume 50, Issue 2, November (125-150).

Chu, S. H. and S. Freund (1996), "Volatility Estimation for Stock Index Options: A GARCH Approach", Quarterly Review of Economics and Finance, Vol. $36(431-450)$.

Clemen, R. T. (1989), "Combining Forecasts: A Review and Annotated Bibliography”, International Journal of Forecasting, Vol. 5 (559-583).

Clements, M. P. and Hendry, D. F. (1998), Forecasting Economic Time Series, Cambridge: Cambridge University Press.

Day, T. E. and C. M. Lewis (1992), "Stock Market Volatility and the Information Content of Stock Index Options", Journal of Econometrics, Vol. 52 (267287).

Diebold, F. X. and R. S. Mariano (1995), “Comparing Predictive Accuracy”, Journal of Business and Economic Statistics, Vol. 13 (253-263).

Ederington, L. and W. Guan (2002), "Is implied Volatility an Informationally Efficient and Effective Predictor of Future Volatility?", Journal of Risk, Vol. 4 (3).

Engle, R. F. (1982), “Autoregressive Conditional Heteroskedasticity with Estimates of the Variance of U.K. Inflation", Econometrica, 50, (987-1008).

Engle, R. F. (2000), "Dynamic Conditional Correlation - A Simple Class of Multivariate GARCH Models", SSRN Discussion Paper 2000-09, University of California, San Diego, May 2000.

Engle, R. F. and K. Kroner (1995), "Multivariate Simultaneous Generalized ARCH", Econometric Theory, 11 (122-150).

Fang, Y. (2002), "Forecasting Combination and Encompassing Tests", International Journal of Forecasting, Vol. 1, Elsevier Science B. V.

Figlewski, S. (1997), "Forecasting Volatility, Financial Markets", Institutions, and Instruments, Vol. 6 (2-87). 
Predictive Accuracy of Futures Options Implied Volatility:
The Case of the Exchange Rate Futures Mexican Peso-US Dollar

Fleming, J. (1998), “The Quality of Market Volatility Forecasts Implied by S \& P 100 Index Option Prices”, Journal of Empirical Finance, Vol. 5 (317-345).

Giot, P. (2003), "Implied Volatility Indexes and Daily Value-at-Risk Models", Working paper, Department of Business Administration \& CEREFIM at University of Namur, Belgium.

Granger, C. W. J. and R. Ramanathan (1984), "Improved Methods of Combining Forecasts", Journal of Forecasting, Vol. 3 (197-204).

Haigh, M. S. and M. T. Holt (2000), "Hedging Multiple Price Uncertainty in International Agricultural Trade", American Journal of Agricultural Economics, Vol. 82, No. 4, November, (881-896).

Harvey, C. R. and R. E. Whaley (1992), "Dividends and S\&P 100 Index Options", Journal of Futures Markets, Vol. 12 (123-137).

Hull, J. (2003), Options, Futures and Other Derivatives, $5^{\text {th }}$ Edition, Prentice Hall.

Jorion, P. (1995), "Predicting Volatility in the Foreign Exchange Market", The Journal of Finance, Vol. 50 (507-528).

Kroner, K., K. P. Kneafsey and S. Claessens (1994), "Forecasting Volatility in Commodity Markets", Journal of Forecasting, Vol. 14 (77-95).

Lamoureux, C. G. and W. D. Lastrapes (1993), "Forecasting Stock Return Variance: Toward an Understanding of Stochastic Implied Volatilities", The Review of Financial Studies, Vol. 6 (293-326).

Levich R. M. 1998, International Financial Markets: Prices and Policies, Boston, Mass.: Irwin McGraw-Hill.

Makridakis, S. (1989), "Why Combining Works?", International Journal of Forecasting, Vol. 5, (601-603).

Manfredo, M., R. M. Leuthold and S. H. Irwin (2001), "Forecasting Cash Price Volatility of Fed Cattle, Feeder Cattle and Corn: Time Series, Implied Volatility and Composite Approaches", Journal of Agricultural and Applied Economics, Vol. 33, Issue 3, December (523-538).

Martens, M. and J. Zein (2002), "Predicting Financial Volatility: High-Frequency Time-Series Forecasts vis-à-vis Implied Volatility”, Mimeo, Erasmus University Rotterdam. 
Neely, C.J. (2002), "Forecasting Foreign Exchange Volatility: Is implied Volatility the Best We Can Do?", Federal Reserve Bank of St. Louis, Workingpaper 2002-017.

Ng, V. K and S. C. Pirrong (1994), "Fundamentals and Volatility: Storage, Spreads, and the Dynamic of Metals Prices", Journal of Business, 67 (203-230).

Park, D. W. and W. G. Tomek (1989), "An Appraisal of Composite Forecasting Methods", North Central Journal of Agricultural Economics, Vol. 10 (1-11).

Pojarliev, M. and W. Polasek (2000), "Portfolio Construction by Volatility Forecasts: Does the Covariance Structure Matter?", Financial Markets and Portfolio Management, 2003, 17 (1), pp. 103-117.

Poon, S-H. and C. Granger (2003), "Forecasting Volatility in Financial Markets: A Review", forthcoming in the Journal of Economic Literature.

Pong, S., M. Shackleton, S. Taylor and X. Xu (2003), "Forecasting Currency Volatility: A Comparison of Implied Volatilities and AR(FI)MA models, forthcoming", Journal of Banking and Finance.

Ng, V. K and S. C. Pirrong (1994), "Fundamentals and Volatility: Storage, Spreads, and the Dynamic of Metals Prices", Journal of Business, 67 (203-230).

Samuelson, P. (1965), "Proof that Properly Anticipated Prices Fluctuate Randomly", Industrial Management Review, 6 Spring (41-49).

Schroeder, T. C., M. L. Albright, M. R. Langemeier and J. Mintert (1993), "Factors Affecting Cattle Feeding Profitability", Journal of the American Society of Farm Managers and Rural Appraisers, 57 (48-54).

Susmel, R. and R. Thompson (1997), "Volatility, Storage and Convenience Evidence from Natural Gas Markets", Journal of Futures Markets, Vol. 17, No. 1 (17-43).

Taylor, S. J. (1985), "The Behaviour of Futures Prices Overtime", Applied Economics, 17, 4 Aug. (713-734).

Wei, A. and R. M. Leuthold (1998), "Long Agricultural Futures Prices: ARCH, Long Memory, or Chaos Processes", OFOR Paper Number 98-03.

$\mathrm{Xu}, \mathrm{X}$. and S. J. Taylor (1995), "Conditional Volatility and the Informational Efficiency of the PHLX Currency Options Market", Journal of Banking and Finance, Vol. 19 (803-821). 
Predictive Accuracy of Futures Options Implied Volatility:

The Case of the Exchange Rate Futures Mexican Peso-US Dollar

\section{APPENDIX}

\section{Figure 1}

The Realised Volatility of the Futures Price and the Natural Logarithm of the Spot and

Futures Prices of the Exchange Rate Peso-USD

(Realised Volatility on the top part of the figure)

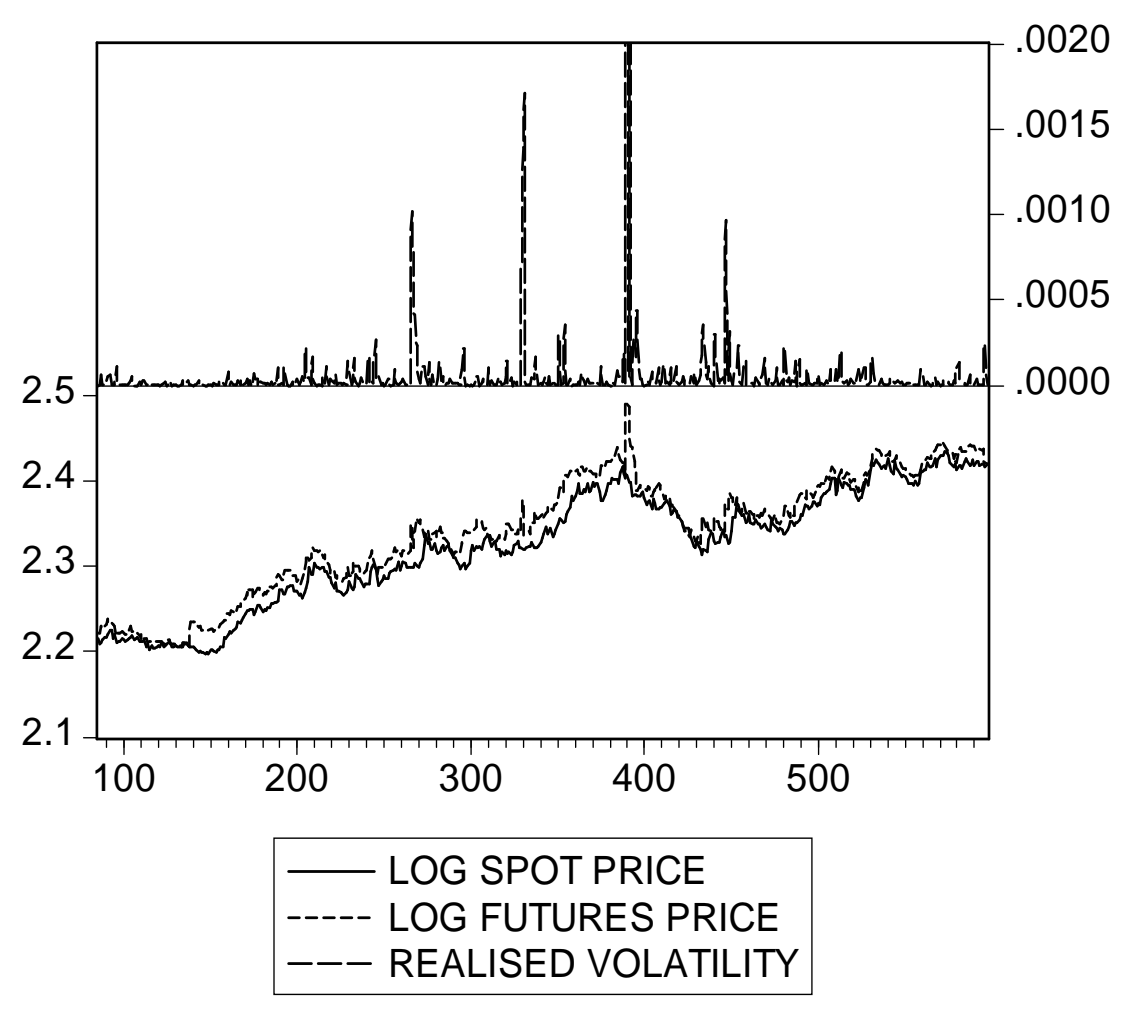


Guillermo BenAVides

TABLe 1

Descriptive Statistics for the Realised Volatility and the

Volatility Forecasting Models of the

Daily Futures Price Returns

of the Mexican Peso-USD Exchange Rate

\begin{tabular}{c|ccccc}
\hline Model & Mean & Variance & Skewness & Kurtosis & N \\
\hline $\begin{array}{c}\text { Realised } \\
\text { volatility }\end{array}$ & $6.40 \times 10^{-5}$ & $1.52 \times 10^{-7}$ & 17.7230 & 356.6332 & 513 \\
GARCH(1,1) & $6.75 \times 10^{-5}$ & $1.70 \times 10^{-8}$ & 11.1848 & 156.0621 & 595 \\
Bi-variate & $7.43 \times 10^{-5}$ & $2.3 \times 10^{-8}$ & 10.6991 & 142.4607 & 595 \\
BEKK(1,1) & & & & & \\
Tri-variate & $6.83 \times 10^{-5}$ & $1.4 \times 10^{-8}$ & 9.8068 & 119.1293 & 595 \\
$\begin{array}{c}\text { BEKK(1,1) } \\
\text { BS option } \\
\text { implied }\end{array}$ & 0.000125 & $1.7 \times 10^{-8}$ & 3.0657 & 14.4143 & 513 \\
$\begin{array}{c}\text { BAW option } \\
\text { implied }\end{array}$ & 0.000125 & $1.7 \times 10^{-8}$ & 3.0663 & 14.4187 & 513 \\
$\begin{array}{c}\text { Composite } \\
\text { forecast }\end{array}$ & $9.68 \times 10^{-5}$ & $9.0 \times 10^{-9}$ & 3.5656 & 20.3474 & 513 \\
\hline
\end{tabular}

This table reports the descriptive statistics of the realised volatility and the volatility forecasting models for the daily futures prices returns of the Mexican peso-USD exchange rate. The daily BS option implied volatility is computed using the Black-Scholes model (1973) and the BAW option implied volatility is calculated using an approximating American option price formula as described in Barone-Adesi and Whaley (1987). The options data are call options at-themoney (or the closest to at-the-money) with at least fifteen days prior to expiration. The realised volatility used to obtain the composite forecast model 
Predictive Accuracy of Futures Options Implied Volatility:

The Case of the Exchange Rate Futures Mexican Peso-US Dollar

is the annualised ex-post daily futures return volatility for the respective sample period under analysis. The sample size for the $\operatorname{GARCH}(1,1)$, the bi-variate and tri-variate $\operatorname{BEKK}(1,1)$ models is 597 observations (two observations are lost because of the lags in the models) from $3^{\text {rd }}$ September 2001 to $5^{\text {th }}$ January 2004. The sample size for the realised volatility, the option implied and the composite models is 513 observations from $2^{\text {nd }}$ January 2002 to $5^{\text {th }}$ January 2004. $N=$ Number of observations.

Figure 2

The Realised Volatility and the Volatility Estimates

from the Historical Models

(Realised Volatility on the top part of the figure)

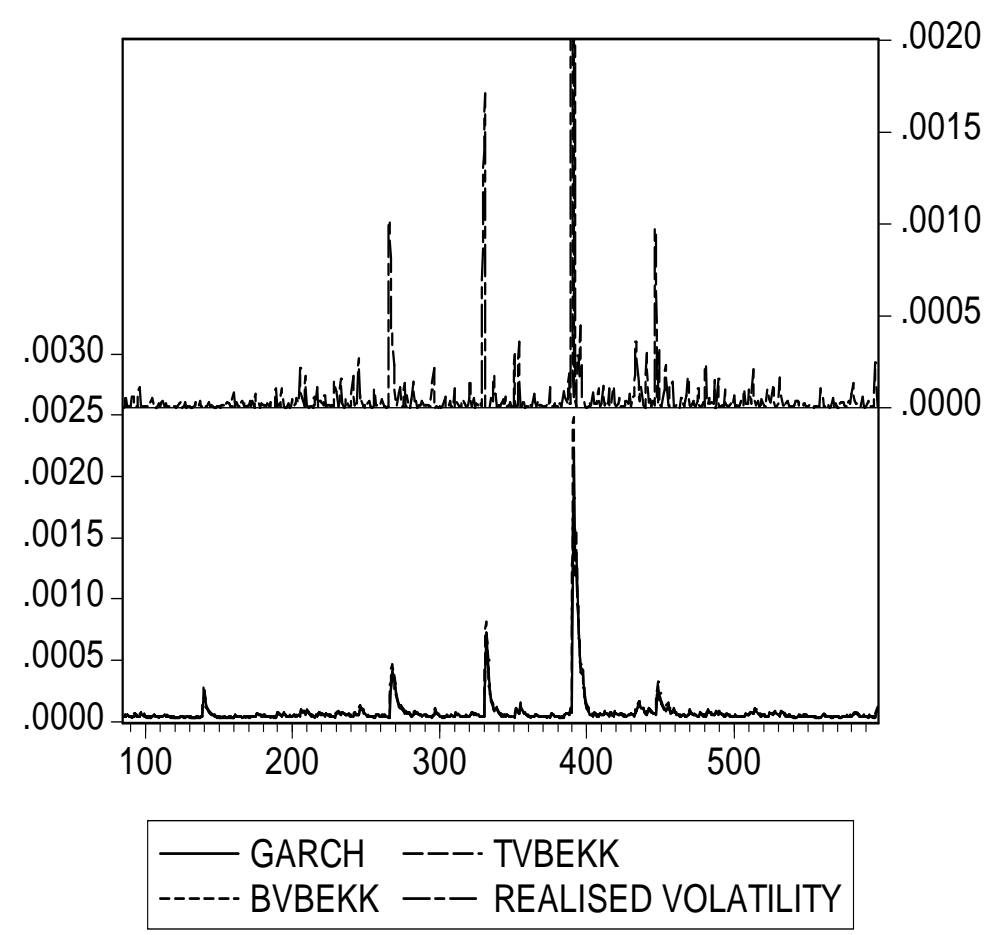


Guillermo BenAvides

Figure 3

The Realised Volatility and the Volatility Estimates from the Option Implied and the Composite Model (Realised Volatility on the top part of the figure)

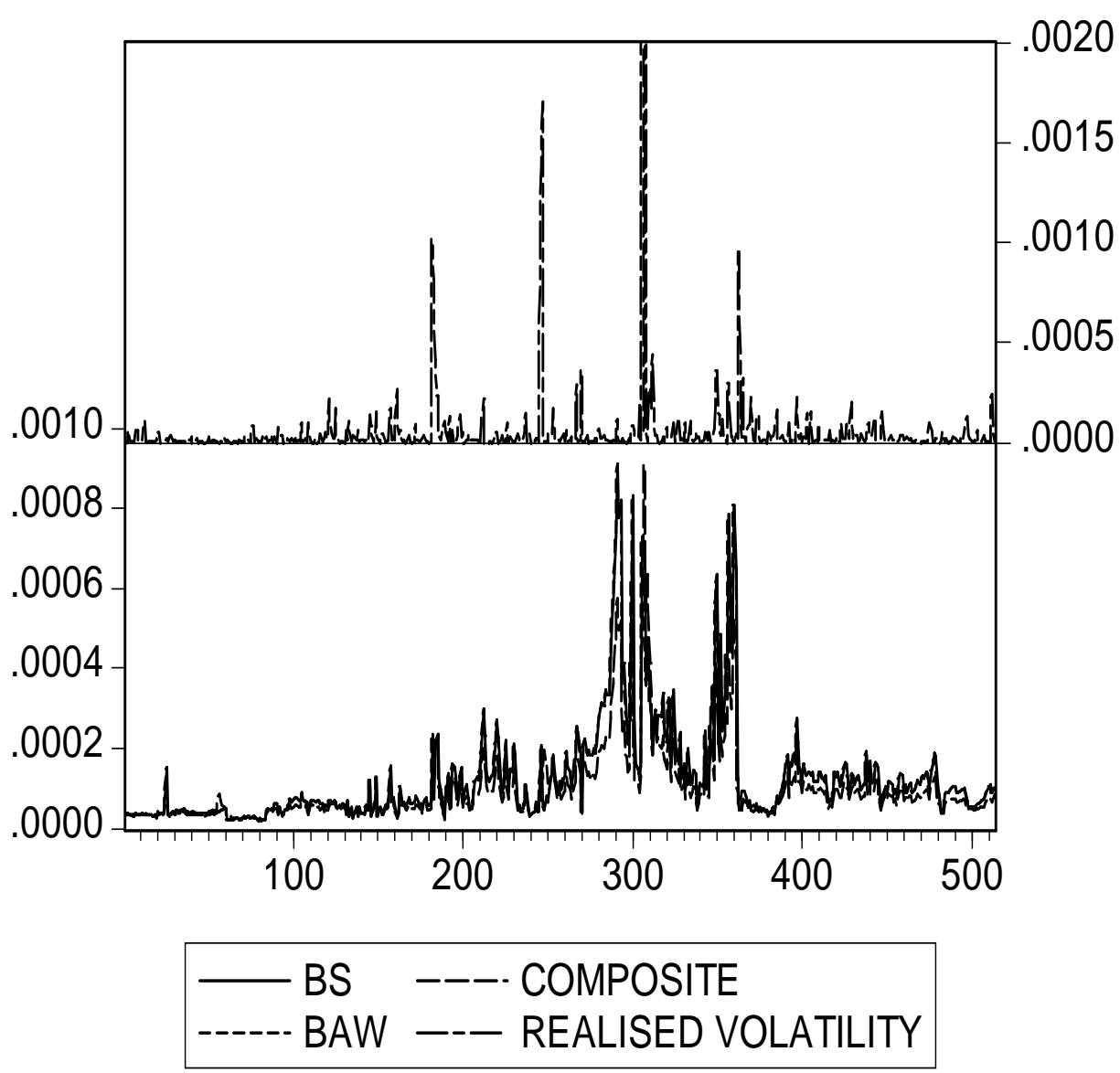


Predictive Accuracy of Futures Options Implied Volatility:

The Case of the Exchange Rate Futures Mexican Peso-US Dollar

\section{TABLE 2}

\section{In-sample OLS Estimates for Weights in the Composite Model}

\begin{tabular}{ccccc}
\hline INDEPENDENT & VARIABLES & & ADJ. $R^{2}$ & DW \\
& & & \\
INTERCEPT & TVBEKK $(1,1)$ & BS OPTION & & \\
& & IMPLIED & & \\
& & & & \\
\hline $3.35 \times 10^{-5}$ & 0.4278 & N.A. & 0.0191 & 2.1576 \\
$\left(1.96 \times 10^{-5}\right)^{*}$ & $(0.1357)^{* *}$ & & & \\
1.7075 & 3.1522 & & & \\
& & & & \\
$-2.14 \times 10^{-5}$ & N.A. & 0.6814 & 0.0528 & \\
$\left(2.32 \times 10^{-5}\right)$ & & $(0.1277)^{* *}$ & & \\
-0.9225 & & 5.3343 & & \\
& & & & \\
$-3.28 \times 10^{-5}$ & 0.2706 & 0.6183 & 0.0599 & 2.1136 \\
$\left(2.38 \times 10^{-5}\right)$ & $(0.1371)^{* *}$ & $(0.1314)^{* *}$ & & \\
-1.3746 & 1.9732 & 4.7077 & & \\
& & & & \\
\hline
\end{tabular}

This table presents estimates of OLS regressions of the variables in the second row (independent variables) against the realised volatility of the exchange rate. Third row presents the estimates of the regression of the realised volatility against the historical TVBEKK $(1,1)$ model. Fourth row presents the estimates of the regression of the realised volatility against the BS implied volatility model. The last column presents the estimates of the regression of the realised volatility against both of the models. The weights are taken from the last row. Standard errors are shown in brackets. Italics $=t$-statistic. $(* *)$ Indicates the coefficient is statistically significant at the $5 \%$ confidence level; (*) indicates the coefficient is statistically significant at the $10 \%$ confidence level. ADJ. $R^{2}=$ Adjusted coefficient of determination. $\mathrm{DW}=$ Durbin Watson statistic. The sample size for the estimates of the regressions is 513 observations from $2^{\text {nd }}$ January 2002 to $5^{\text {th }}$ January 2004. N.A $=$ Not applicable. 
Guillermo BenAVides

TABle 3

In-sample MSE for the Exchange Rate Forecasts

\begin{tabular}{l|ccc}
\hline \multicolumn{1}{c|}{ FORECAST } & MSE & P-VALUE & RANK \\
\multicolumn{1}{c|}{ MODEL } & & & \\
\hline GARCH(1,1) & $1.57586 \times 10^{-7}$ & 0.00205 & 5 \\
BVBEKK $(1,1)$ & $1.61497 \times 10^{-7}$ & 0.00015 & 6 \\
TVBEKK(1,1) & $1.5466 \times 10^{-7}$ & 0.00055 & 4 \\
BS option implied & $1.49786 \times 10^{-7}$ & 0.00046 & 2 \\
$\begin{array}{l}\text { BAW option } \\
\text { implied }\end{array}$ & $1.49788 \times 10^{-7}$ & 0.00187 & 3 \\
Composite model & $1.44023 \times 10^{-7 *}$ & N.A & 1 \\
\hline
\end{tabular}

This table reports MSE of the volatility forecasting models for the daily futures prices returns for the Mexican peso-USD exchange rate. The daily option implied volatility is computed using the Black-Scholes (1973) model and an approximating American option price formula as described in Barone-Adesi and Whaley (1987). The options data are call options at-the-money (or the closest to at-themoney) with at least fifteen days prior to expiration. The realised volatility used to obtain the MSE is the annualised ex-post daily futures return volatility for the sample period under analysis. P-Values are referred to the procedure to obtain statistical significances in MSE for each model against the composite model according to Diebold and Mariano (1995). Rank $1=$ Highest, $6=$ Lowest. The sample size for the $\operatorname{GARCH}(1,1)$ and the $\operatorname{BEKK}(1,1)$ models is 597 observations from $3^{\text {rd }}$ September 2001 to $5^{\text {th }}$ January 2004. The sample size for the implied 
Predictive Accuracy of Futures Options Implied Volatility:

The Case of the Exchange Rate Futures Mexican Peso-US Dollar

and the composite models is 513 observations from $2^{\text {nd }}$ January 2002 to $5^{\text {th }}$ January 2004. The sample size to calculate the MSE is the same as for the implied and the composite models i.e. 513 observations from $2^{\text {nd }}$ January 2002 to $5^{\text {th }}$ January 2004. (*) Indicates the smallest value. N.A $=$ Not applicable.

\section{TABLE 4}

In-sample OLS Estimates for the out-of-the-sample Evaluation of the Exchange Rate Volatility Peso-USD

\begin{tabular}{|c|c|c|c|c|}
\hline INDEPENDENT & VARIABLES & & ADJ. $R^{2}$ & DW \\
\hline \multirow[t]{2}{*}{ INTERCEPT } & $\operatorname{TVBEKK}(1,1)$ & BS OPTION & & \\
\hline & & IMPLIED & & \\
\hline $4.87 \times 10^{-7}$ & 0.7408 & N.A. & 0.0777 & 1.2801 \\
\hline$\left(1.38 \times 10^{-5}\right)$ & $(0.1601)^{* *}$ & & & \\
\hline-0.0353 & 4.6263 & & & \\
\hline$-1.36 \times 10^{-5}$ & N.A. & 0.8655 & 0.0681 & 1.0284 \\
\hline$\left(1.69 \times 10-^{5}\right)$ & & $(0.2008)^{* *}$ & & \\
\hline-0.8049 & & 4.3087 & & \\
\hline $4.50 \times 10^{-5}$ & 0.6526 & 0.7452 & 0.1271 & 1.2419 \\
\hline$\left(1.80 \times 10^{-5}\right)^{* *}$ & $(0.1578)^{* *}$ & $(0.1969)^{* *}$ & & \\
\hline-2.4930 & 4.1348 & 3.7834 & & \\
\hline
\end{tabular}

This table presents estimates of OLS regressions of the variables in the second row (independent variables) against the realised volatility of the respective commodity (dependent variable). Standard errors are shown in brackets. Italics $=t$-statistic. $(* *)$ Indicates the coefficient is statistically significant at the $5 \%$ confidence level; $\left(^{*}\right)$ indicates the coefficient is statistically significant at the 
$10 \%$ confidence level. ADJ. $R^{2}=$ Adjusted coefficient of determination. DW $=$ Durbin Watson statistic. The sample size for the $\operatorname{BEKK}(1,1)$ model is 5297 observations from $2^{\text {nd }}$ January 1975 to $3^{\text {rd }}$ January 1996. The sample size for the implied and the composite models is 757 observations from $2^{\text {nd }}$ January 1993 to $3^{\text {rd }}$ January 1996. N.A = Not applicable.

\section{TABLE 5}

Out-of-the-sample MSE for the Exchange Rate Forecasts

\begin{tabular}{l|ccc}
\hline \multicolumn{1}{c|}{$\begin{array}{c}\text { FORECAST } \\
\text { MODEL }\end{array}$} & MSE & P-VALUE & RANK \\
\hline GARCH(1,1) & $2.84 \times 10^{-7}$ & 0.0004 & 6 \\
BVBEKK $(1,1)$ & $2.77 \times 10^{-7}$ & 0.0003 & 5 \\
TVBEKK(1,1) & $2.76 \times 10^{-7}$ & 0.0002 & 4 \\
BS option implied & $2.65 \times 10^{-7^{*}}$ & N.A & 1 \\
BAW option & $2.65 \times 10^{-7^{*}}$ & N.A & 1 \\
implied & $2.69 \times 10^{-7}$ & 0.0001 & 3 \\
Composite model & & & \\
\hline
\end{tabular}

This table reports the out-of-the-sample MSE of the volatility forecasting models for the daily futures prices returns of the exchange rate Mexican peso-USD. The daily option implied volatility is computed using the Black-Scholes (1973) model and an approximating American option price formula as described in Barone-Adesi and Whaley (1987). The options data are call options at-themoney (or the closest to at-the-money) with at least fifteen days prior to 
Predictive Accuracy of Futures Options Implied Volatility:
The Case of the Exchange Rate Futures Mexican Peso-US Dollar

expiration. The realised volatility used to obtain the MSE is the annualised expost daily futures return volatility for the sample period under analysis. Rank 1 $=$ Highest, $6=$ Lowest. The in-sample size for all the models is 256 observations (about half the total number of observations) from $2^{\text {nd }}$ January 2002 to $30^{\text {th }}$ December 2002. The out-of-the-sample forecast evaluation period consists of 257 observations from $31^{\text {st }}$ December 2002 to $5^{\text {th }}$ January 2004. The jumpoff period is $31^{\text {st }}$ December 2002. (*) Indicates the smallest value. N.A = Not applicable. 